\title{
The impact of the mountain climate on the oxygen supply system in human at different altitude
}

PAWEŁ RADZIEJOWSKI ${ }^{1}$, MARIA RADZIEJOWSKA ${ }^{2}$, WALERY ZUKOW ${ }^{3}$

${ }^{1,2}$ Institute of Health Sciences and Nutrition, Faculty of Management, Czestochowa University of Technology, Czestochowa, POLAND

${ }^{3}$ Department of Spatial Management and Tourism, Faculty of Earth Sciences, Nicolaus Copernicus University, Torun, POLAND

Published online: January 31, 2019

(Accepted for publication December 05, 2018)

DOI:10.7752/jpes.2019.s1016

\section{Abstract}

At the present time the mountainous climate as the ecosystem has been widely used in curative and sport practice with therapeutic, prophylactic and recreational purposes. This work aimed to study reactions of external breathing, blood circulation, blood and tissue respiration during ascending to mountain at various altitudes from $2100 \mathrm{~m}, 3500 \mathrm{~m}$ and $4200 \mathrm{~m}$ above sea level. To attain this goal, investigations were carried out to study changes in the functional respiratory system (FRS) and body's oxygen regimes (BOR) in the people who have been well adapted to hypoxia of varying origin - sportsmen (adapted to physical loads of varying intensity) and altitude climbers (sportsmen, whose professional activity takes place under low and at time very low partial oxygen pressure in the inhaled air). Twenty-eight sport women and high altitude female climbers underwent complex examinations under normoxy conditions prior to ascending mountains. Later analogous examinations were conducted at the beginning (on day 2-3) of the educational-training session at mid-altitude (Terskol, PreElbrus, $2100 \mathrm{~m}$ above sea level) on day 10 of their stay. Examinations were conducted at altitudes 3500 and 4200 above sea level. Transfer of essentially healthy people, who have not been adapted to hypoxic hypoxia typical for mountains at altitude $2100 \mathrm{~m}$ above sea level, caused health worsening of FRS and BOR control. At altitude $4200 \mathrm{~m}$ above sea level even after 12 day acclimatization the indicators of external respiration were 2-2.5 times higher compared to same normoxy condition. After transfer to altitude $2100 \mathrm{~m}$ above sea level during first days of acclimatization it is desirable to reduce motor activity because under these conditions the state of the main oxygen-transport systems of the organism does not allow sustain work ability at normoxic level. It is desirable that such corrections be made individually with a consideration of data of prior stay at analogous altitude.

Key words: acclimatization, oxygen delivery system, mountain environment.
\end{abstract}

\section{Introduction.}

The key factor of mountainous climate action on the organism, as had as long been proved by Paul Berr, is the oxygen-poor air in which the partial oxygen pressure $\left(\mathrm{pO}_{2}\right)$ is reduced. Many research workers have demonstrated that reduced $\mathrm{pO}_{2}$ in the air (the main high altitude climate factor) brings about essential changes in the functional respiratory system (FRS) and especially in its controlling object - oxygen mass transfer and oxygen consumption by its controlling link, the nervous and endocrine systems (Anokchin P.K., 1975; Kolczynskaya A.Z., 191965-1991).

Function of the FRS working organs (external respiration organs, blood circulation and respiration, tissue respiration) also undergoes changes at reduced $\mathrm{pO}_{2}$ in the inhaled air (Suslov F.P., 1983; Strelkov R.B., 1994). At the present time the mountainous climate is widely used in curative and sport practice with therapeutic, preventive and recreational purposes. At the present time the mountainous climate is widely used in curative and sport practice with therapeutic, preventive and recreational purposes. However no studies have been conducted so far to compare the FRS reactions and body oxygen regimen (BOR) resultant from short-time adaptation of human organism at altitudes $2100 \mathrm{~m}, 3500 \mathrm{~m}$ and $4200 \mathrm{~m}$ above sea level.

Purpose. Our investigation has aimed to study reactions of the working organs of the functional respiratory system, such as: external breathing, blood circulation, blood respiration function and tissue respiration while ascending mountains at different altitudes, starting from $2100 \mathrm{~m}, 3500 \mathrm{~m}$ to 4200 at sea level.

\section{Methods and Study Design.}

To attain this goal, we conducted a series of investigations to study changes of the FSD indicators and BOR parameters in the humans well adapted to hypoxia of various origin like sportsmen who have been adapted to physical loads of varying intensity, altitude climbers-sportsmen whose professional activity proceeded under conditions of low and at times very low partial oxygen pressure in the inhaled air. 
The female sport and altitude climbers underwent complex investigations under normoxia conditions, immediately before ascending the mountains. Thereafter analogous investigations were performed at the beginning (on day 2-3) of the educational-training sessions in mid-altitude (Terskol, Elbrus Region, $2100 \mathrm{~m}$ ). During training sessions at altitude we paid a special attention to organism's reaction to $\mathrm{pO}_{2}$ reduction in the inhaled air during first days of the stay, and the dependence of this reaction on the altitude, change of overall physical work capacity, aerobic productivity, FRS status and body oxygen regimens (BOR).

Altogether twenty-eight women aged $24-26$ years were examined: of them 12 women, who were engaged in cycling (honored master of sports and world class sport masters) with body weight $59.4 \square 1.1 \mathrm{~kg}$ and body height $165.0 \square 2.3 \mathrm{~cm}$, and 4 mountaineers (world class sport masters and sport masters) with body weight $58.0 \square 1.1 \mathrm{~kg}$ and body height $160.0 \square 1.2 \mathrm{~cm}$.

The use was made of the method enabling to assess functional state, aerobic productivity and working capacity based on simultaneous registration of changes in the indicators of respiration, blood flow, blood respiration and gas exchange that was followed by the analysis of oxygen and $\mathrm{pO}_{2}$ transfer speed, the speed of oxygen delivery to the lung $\left(\mathrm{q}_{\mathrm{i}} \mathrm{O}_{2}\right)$ and to the alveoli $\left(\mathrm{q}_{\mathrm{A}} \mathrm{O}_{2}\right)$, the speed of oxygen delivery to the arterial $\left(\mathrm{q}_{\mathrm{a}} \mathrm{O}_{2}\right)$ and mixed venous blood $\left(\mathrm{q}_{\mathrm{v}} \mathrm{O}_{2}\right)$, oxygen consumption rate $\left(\mathrm{VO}_{2}\right)$, oxygen partial pressure in the inhaled $\left(\mathrm{p}_{\mathrm{i}} \mathrm{O}_{2}\right)$ and alveolar gas $\left(\mathrm{p}_{\mathrm{A}} \mathrm{O}_{2}\right)$, oxygen pressure in the arterial $\left(\mathrm{p}_{\mathrm{a}} \mathrm{O}_{2}\right)$ and mixed venous blood $\left(\mathrm{p}_{\mathrm{v}} \mathrm{O}_{2}\right)$, mm $\mathrm{Hg}$; arterial blood oxygen consumption rate $\left(\mathrm{VO}_{2}\right)$, partial oxygen pressure in the inhaled $\left(\mathrm{p}_{\mathrm{i}} \mathrm{O}_{2}\right)$ and alveolar gas $\left(\mathrm{p}_{\mathrm{A}} \mathrm{O}_{2}\right)$, oxygen pressure in the arterial $\left(\mathrm{p}_{\mathrm{a}} \mathrm{O}_{2}\right)$ and mixed venous blood $\left(\mathrm{p}_{\mathrm{v}} \mathrm{O}_{2}\right)$. Analyzed was also the effectiveness and economic of the BOR and the quality of their control; ventilation (VE) and homodynamic (HE) equivalents, oxygen effects of the breathing and cardiac cycles (OEBC) (oxygen pulse, OP) at rest and during exercising [4$6]$. The indicators of lung respiration and gas exchange of the breathing volume (BV) and minute respiration volume (MRV), its frequency (BF), alveolar ventilation (AV) and $A V / M R V$ ratio $\left(\mathrm{AV} / \mathrm{MRV}^{-1}\right)$, gas composition of the inhaled $\left(\mathrm{F}_{\mathrm{I}} \mathrm{O}_{2}, \mathrm{~F}_{\mathrm{I}} \mathrm{CO}_{2}\right)$ and exhaled $\left(\mathrm{F}_{\mathrm{E}} \mathrm{O}_{2}, \mathrm{~F}_{\mathrm{E}} \mathrm{CO}_{2}\right)$ air, volumetric oxygen consumption and carbonic gas discharge, ventilation equivalent and the breathing cycle oxygen effect were measured by means of the DouglasHolden method. The air gas composition was determined by using maspectograph (Ukraine), gas analyzers MMC "Backman" and "Spirolit" (Germany). The minute blood volume was estimated according to the Starr's formula for adults. The heart rate (HR) was measured and fixed in electronic memory of sport-tester PE-3000 (Finland). The arterial blood pressure during testing exercises was measured by the Korotkov's method. Indicators of the blood respiratory function and blood hemoglobin content $(\mathrm{Hb})$ were assessed on photo calorimeter MKMF-1 (Russia). The blood oxygen capacity was calculated according to the Huffner's constant. The blood oxygen saturation $\left(\mathrm{S}_{\mathrm{a}} \mathrm{O}_{2}\right)$ was recorded by pulse oxymeter "Oxyshuttle" (USA).

\section{Results.}

During the first days after ascent to mid-altitude, the high-qualified female cyclists reported change of self-feeling, despite majority of them would have been many times in the mountains. Among self-reported changes, they mentioned a somewhat euphoric mood, quicker movements, more gesticulation and speed-up speech. Effects of hypoxia in some of them were manifesting not only objectively but also subjectively, as there appeared heaviness in the head and in entire body. In rare cases there was a headache, nausea and sleep disorders. Transfer to mid-altitudes (village Terskol, Pre-Elbrus Region, altitude $2100 \mathrm{~m}$ above sea level) caused a compensated hypoxia in the body of the female cyclists, leading to both, an enhancement of the respiration system functioning, as a whole, and to a redistribution of its reserves.

The examinations of the high-qualified female cyclists that we had conducted have showed that their move at $2100 \mathrm{M}$ altitude above sea level resulted in the statistical increase of resting MBR and AV values. Notably, despite some increase of BF, the BV value was greater than at normoxia (Table 1).

Table 1. Change of external breathing values in the high-qualified female cyclists at rest and under plane conditions during first days at mid-altitude (Terskol-1).

\begin{tabular}{|c|c|c|}
\hline Parameters & $\begin{array}{c}\text { Plain } \\
\text { conditions }\end{array}$ & $\begin{array}{c}2100 \mathrm{~m} \text { altitude above sea } \\
\text { level }\end{array}$ \\
\hline Breathing frequency, breaths $/ \mathrm{min}^{-1}$ & $12.0 \square 2.0$ & $14.0 \square 2.0$ \\
\hline Respiration volume, $\mathrm{ml}$ & $475 \square 15$ & $559 \square 21$ \\
\hline Minute respiration volume, $1 / \mathrm{min}^{-1}$ & $5.70 \square 0,30$ & $7.83 \square 0.27$. \\
\hline Alveolar ventilation, $1 / \mathrm{min}^{-1}$ & $4.03 \square 0.02$ & $5.68 \square 0.02$ \\
\hline Alveolar ventilation/Minute respiration volume rate, $\%$ & $70.7 \square 0,3$ & $72.5 \square 0.5$ \\
\hline Oxygen consumption rate, $\mathrm{ml} / \mathrm{min}^{-1}$ & $202 \square 4$ & $209 \square 11$ \\
\hline Oxygen consumption rate/body weight ratio, $\mathrm{ml} / \mathrm{min}^{-1} / \mathrm{kg}^{-}$ & $3.42 \square 0.09$ & $3.54 \square 0.12$ \\
\hline
\end{tabular}

* - Differences from previous examination findings are statistically significant $(\mathrm{p}<0.05)$.

Cardio-vascular system investigations performed immediately after ascent to the mountains showed the increase of resting HR (by $6 \mathrm{~min}^{-1} \pm 1 \mathrm{~min}^{-1}$ ) and minute blood volume (by $384 \mathrm{ml} / \mathrm{min}^{-1} \pm 13 \mathrm{ml} / \mathrm{min}^{-1}$ ), although the systolic volume was not likely changing but had some tendency to a decrease (Table 2). 
Table 2. Change of blood flow and blood respiration function values in the high-qualified female cyclists at rest and under plane conditions during first days at mid-altitude (Terskol-1).

\begin{tabular}{|c|c|c|}
\hline & Plain conditions & $\begin{array}{c}\mathbf{2 1 0 0} \text { m a.s.l. } \\
\text { altitude }\end{array}$ \\
\hline Heart rate, $\mathrm{min}^{-1}$ & $48 \square 3$ & $54 \square 5$ \\
\hline Minute blood volume, $\mathrm{ml} / \mathrm{min}^{-1}$ & $3504 \square 260$ & $3888 \square 220$ \\
\hline $\begin{array}{c}\text { Stroke volume, } \mathrm{ml} \\
\begin{array}{c}\text { Alveolar ventilation/Minute respiration volume } \\
\text { rate, } \%\end{array}\end{array}$ & $1.150 \square 0.15$ & $1.460 \square 0.24$ \\
\hline Arterial blood oxygen saturation, \% & $96.2 \square 0.8$ & $96.5 \square 1.0$ \\
\hline Arterial blood oxygen content, $\mathrm{ml} \backslash \mathrm{l}^{-1}$ & $180.5 \square 1.5$ & $181.0 \square 3.0$ \\
\hline Hemoglobin content, $\mathrm{g} / \mathrm{l}^{-1}$ & $138 \square 4$ & $138 \square 7$ \\
\hline
\end{tabular}

* - Differences from previous examination findings are statistically significant $(\mathrm{p}<0.05)$.

According to our investigation findings, during first days of the stay of study sports- women's in the surrounding with a reduced $\mathrm{pO}_{2}$ in the inhaled air there was no increase of hemoglobin and blood oxygen capacity compared to normoxia. The arterial oxygen content $\left(\mathrm{CaO}_{2}\right)$ also was within normoxia values. The $\mathrm{SaO}$ value had a tendency toward an increase during first days at altitude due to compensated enhancement of the system external breathing function (See Table 2).

Immediately upon reaching $2100 \mathrm{M}$ altitude above sea level, the BOR values of study subjects became more economical. There occurred a noticeable rise of the ventilation equivalent: each consumed oxygen liter was provided with greater (by 32.6 $\pm 1.5 \%$ ) amount of the ventilated air. The hemodynamic equivalent grew although not so markedly as the VE. The values of OP and BCOE were lower during first days of stay at altitude in the comparison with the results of examination that had been conducted at resting state on the plain (Table 3).

Table 3. Change of functional respiratory system economical effect values in the high-qualified female cyclists at rest and under plain conditions during first days at mid-altitude (Terskol-1)

\begin{tabular}{|c|c|c|}
\hline Parameters & $\begin{array}{c}\text { Plain } \\
\text { conditions }\end{array}$ & $\begin{array}{c}\mathbf{2 1 0 0} \\
\text { altitude }\end{array}$ \\
\hline Ventilation equivalent, nominal units & $28.2 \square 0.4$ & $37.4 \square 1.5$ \\
\hline Breathing cycle oxygen effect, ml/breath $^{-1}$ & $16.8 \square 1.4$ & $14.9 \square 0.8$ \\
\hline Hemodynamic equivalent, nominal units $^{-1}$ & $17.3 \square 0.3$ & $18.6 \square 0.6$ \\
\hline Oxygen pulse, $\mathrm{ml} /$ stroke $^{-1}$ & $4.2 \square 0.2$ & $3.9 \square 0.1$ \\
\hline
\end{tabular}

* - Differences from previous examination findings are statistically significant $(\mathrm{p}<0.05)$.

Although in previous years all sports women had not infrequently attended training sessions in the mountains, not a single one of them could accomplish 300 Watt $\square 10$ Watt performance. That is, they failed to endure exercising under normal atmosphere pressure which they had performed before training session at altitudes. Moreover, as was revealed during complex examination, additive action of two types of hypoxia caused greater shifts in the FRS status during intensive physical loading (Table 4). Even greater changes were recorded during investigation of maximal hemodynamic possibilities under same conditions. During maximal oxygen consumption (MOC) loading, despite the $6 \mathrm{~min}^{-1} \pm 1 \mathrm{~min}^{-1}$ heart rate increase, the MRV value was lower by $1.67 \% \pm 0.03 \%$ mainly because of the notably lower (by $7.4 \% \pm 1.14 \%$ ) SV of the blood compared to its plain meaning (See Table 4).

Table 4. Changes of external breathing, blood flow and blood respiratory function in female cyclists under MOC exposure on the plain during first days at mid-altitude (Terskol-1).

\begin{tabular}{|c|c|c|}
\hline & Plain conditions & 2100 m altitude above sea level \\
\hline Breathing frequency, breaths/min & $54.0 \square 2.0$ \\
\hline Respiration volume, $\mathrm{ml}$ & $47.0 \square 2.0$ & $1844 \square 16$ \\
\hline Minute respiration volume, $1 / \mathrm{min}^{-1}$ & $1874 \square 15$ & $99.60 \square 2.12$ \\
\hline Alveolar ventilation, $/ \mathrm{min}^{-1}$ & $88.1 \square 1.02$ & $81.1 \square 1.9$ \\
\hline Alveolar ventilation/Minute respiration volume, $\%$ & $74.5 \square 1.4$ & $81.50 \square 0.50$ \\
\hline Oxygen consumption rate, $\mathrm{ml} / \mathrm{min}^{-1}$ & $84.6 \square 0.08$ & $2792 \square 38$ \\
\hline Oxygen consumption rate/body mass ratio, $\mathrm{ml}^{-1} \mathrm{~min}^{-1} / \mathrm{kg}^{-1}$ & $5172 \square 43$ & $47.32 \square 1.18$ \\
\hline Heart contraction frequency, $\mathrm{min}^{-1}$ & $192 \square 3$ & $198 \square 5$ \\
\hline Minute blood volume, $\mathrm{ml} / \mathrm{min}^{-1}$ & $24.96 \square 0.12$ & $24.55 \square 0.15$ \\
\hline Stroke volume, $\mathrm{ml}$ & $130 \square 5$ & $121 \square 4$ \\
\hline Blood oxygen capacity, $\mathrm{ml} / \mathrm{l}^{-1}$ & $192.8 \square 4.5$ & $193.1 \square 3.3$ \\
\hline Arterial blood oxygen saturation, $\%$ & $88.0 \square 0.5$ & $85.0 \square 0.5$ \\
\hline Arterial blood oxygen content, $\mathrm{ml} / \mathrm{l}^{-1}$ & $169.7 \square 1.5$ & $164.1 \square 1.2$ \\
\hline Arterial-venous difference by oxygen, $\mathrm{ml} / \mathrm{l}^{-1}$ & $127.1 \square 2.4$ & $113.8 \square 1.2$ \\
\hline Venous blood oxygen content, $\mathrm{ml} / \mathrm{l}^{-1}$ & $42.6 \square 2.15$ & $50.30 \square 2.20$ \\
\hline Venous blood oxygen saturation, $\%$ & $22.1 \square 0.44$ & $26.10 \square 0.90$ \\
\hline * Differences from previous examination findings are statistically significant (p<0.05).
\end{tabular}


During first days at altitudes, no drastic rise of hemoglobin content of the blood took place. In actual fact, on day $2-3$ the blood hemoglobin content practically did not grow thus not allowing notably increase the blood oxygen capacity. The arterial blood oxygen content fell down by $3.41 \% \pm 0.31 \%$ because oxygen saturation due to maximal exercising intensity in the mountains appeared to be lower $(85.0 \% \pm 0.5 \%)$ than that which had been seen in the analogous conditions on the plain $(88.0 \% \pm 0.5 \%)$ (See Table 4).

In our opinion, it would be interesting to make a comparison of the reactions of highly qualified cyclists and mountain climbers to the move in the mountains.

\section{Discussion.}

Regarding our observations, when staying at $2100 \mathrm{~m}$ altitude our study mountain climbers did not reveal any health worsening during first days that is so characteristic for sportsmen of other specializations and especially for untrained individuals who have moved to mid-altitude. When being examined by us at resting state on day $2-3$, the female mountain climbers did not show any essential changes in the FRS values compared to normoxic conditions. Comparison of the examination results obtained by us in the female cyclists with the data of the age-matched high-class mountain climbers has shown that certain increase of MRV recorded during first days of stay at altitude has been provided only at the expense of BV increase because the BF value did not grow in the comparison with normoxic data. The oxygen consumption rate at rest did not change and remained at the plain level meaning $(\mathrm{p}>0.05)$. Neither the HR value rose at this altitude, but the SV and MBV indices had a slight tendency toward an increase $(\mathrm{p}>0.05)$.

This indicates greater effectiveness of the external respiration and higher economic effect of the BOR in the mountain climbers at the given altitude in the comparison with analogous functional indices of the female cyclists at mid-altitude. Moreover, this finding is also confirmed by that with a lesser MRV at $2100 \mathrm{~m}$ altitude the alveolar ventilation almost did not differ from AV in the female cyclists.

Long-term training in mountain climbing has also determined the greater body resistance to lower $\mathrm{pO}_{2}$ of the arterial blood and the higher $\mathrm{pCO}_{2}$ in it. At $2100 \mathrm{~m}\left(\mathrm{p}_{\mathrm{i}} \mathrm{O}_{2} 123-130 \mathrm{~mm} \mathrm{Hg}\right)$, the high qualification mountain climbers showed the value for oxygen partial pressure in the alveoli at rest being $76.13 \pm 0.9 \mathrm{~mm} \mathrm{Hg}$ and its pressure $70.2 \pm 1.2 \mathrm{~mm} \mathrm{Hg}$ in the arterial blood.

\section{Conclusions}

In summing up, the move of essentially healthy individuals, non-adapted to hypoxic hypoxia, to $2100 \mathrm{~m}$ a.s.l. altitude causes the worsening of functional respiratory system and governing body oxygen regimens health that is manifest in the decrease of working ability and aerobic productivity. These shifts are the greater the more reduced partial oxygen pressure in the inhaled air. At $4200 \mathrm{~m}$ a.s.l. altitude, even after 12-day acclimatization the external respiration indices were 2-2.5-fold higher than those that can be found at normoxia.

After the ascent at $2100 \mathrm{~m}$ a.s.l. altitude, during first days of the stay it is desirable that the level of mobility be reduced because the state of the main body oxygen delivery systems of the sportsmen does not allow keep working ability at normoxic level. It is desirable that such correction be done individually with a consideration of previous ascents to analogues altitudes.

It is necessary to note that in the sportsmen of cyclic kind of sport the level of maximal oxygen consumption under plain conditions is much higher than in the mountain climbers. However, the move to mid-altitude areas of even high qualification sportsmen, who not infrequently had training sessions in the mountains, causes the worsening of working ability. In the mountain climbers, whose professional activity proceeds under conditions of low and extremely low partial oxygen pressure in the inhaled air, no analogous changed have been observed by us.

\section{Declarations}

\section{Ethics approval and consent to participate}

The research related to human use complied with all the relevant national regulations, institutional policies, and was in accordance with the tenets of the Helsinki Declaration. The study protocol was approved by the Ethical Committee of Czestochowa University of Technology, Czestochowa, Poland. During realization of tests, all participants provided informed consent and used all measures for maintaining anonymity of participants.

Data - Data sharing not applicable to this article as no datasets were generated or analyzed during the current study. Please contact author for data requests.

Consent to publish - Not applicable

Competing interests - The authors declare that they have no competing interests.

Funding - No funding

\section{Authors' contributions}

PR, MR participated in the design of this study. PR, MR performed the statistical analyses. PR, MR, WZ drafted the manuscript. PR, MR were involved in data collection and/or made important intellectual contributions to the interpretation of data and the writing of paper. All authors critically revised and approved the final version.

Acknowledgements - Not applicable 


\section{References}

Anokhin P.K. Essays on the Physiology of the Functional Systems. Moscow: Meditsina, 1975. [in Russian] Kolchinskaya A.Z. Concerning the acclimatization of the trained and untrained organisms to high altitude climate and the role of high altitude acclimatization in increasing physical endurance. Presentation at All-Union Scientific Conference "Acclimatization training of sportsmen in the mountains". Alma-Ata, 1965, pp. 53-54. [in Russian]

Kolchinskaya A. Z. About regulation of the body oxygen regimens (BOR) in the aging. The $9^{\text {th }}$ International Congress of Gerontology. Abstract Book. Kiev: Midgiz Publ., 1972, vol. 3, p. 338. [in Russian]

Kolchinskaya A. Z. Body Oxygen Regimens in the Children and Youths. Kiev: Naukova Dumka Publ., 1973. [in Russian]

Kolchinskaya A. Z., Mankovskaya I.N., Misyura A.G. Breathing and Body Oxygen Regimens in the Dolphins. Kiev: Naukova Dumka Publ., 1980. [in Russian]

Kolchinskaya A. Z. Oxygen. Physical Status. Working Ability. Kiev: Naukova Dumka Publ., 1990. [in Russian]

Strelkov R.B. Normobaric hypoxic therapy. Methodological recommendations. Moscow: Health Ministry of Russia Publ., 1994, 13 p. [in Russian]

Suslov F.P. Training at mid-altitude as a means for increasing sport skills. Author's Thesis seeking a Doctor of Science degree. Moscow, 1983. 48 p. [in 